\title{
Unpacking Our White Privilege: Reflecting on Our Teaching Practice
}

\author{
Dawn Burleigh and Sarah Burm
}

Western University

\begin{abstract}
MacIntyre (1981) asks, “Of what stories do I find myself a part?” (p. 201). As teachers working in an Indigenous context, we found ourselves telling stories that had moments of tension between our Eurocentric ways of knowing and the Indigenous context in which we taught. This intersection has prompted our research. We ask two questions in this inquiry: What can our experiences as non-Indigenous teachers in an Indigenous community offer us in our understanding as new researchers in the field of Indigenous education, and how can our teaching narratives further preservice teachers' understandings of teaching Indigenous students? Through critical White studies, our research examines White privilege, power, and position and begins to unearth the experiences of teaching as non-Indigenous educators in a remote Indigenous community in Ontario, Canada. Narrative inquiry and autoethnographic methods connect our stories to greater social, political, and cultural discourses. These stories serve to disrupt the dominant discourse that divides and others the complexities of Indigenous education. This work will interrogate and unpack our White privilege and power and will serve to assist preservice teachers in their understanding of teaching within Indigenous contexts.
\end{abstract}

Keywords: Indigenous education; narrative inquiry; critical White studies; teacher education 


\section{Unpacking Our White Privilege: Reflecting on Our Teaching Practice}

\section{Remembering}

It was while living and teaching as White educators in a remote First Nations community that our dialogue began about our teaching experiences. As teachers working in the same educational system in which we were students, we began to recognize how our Whiteness and our Eurocentric educational experiences had shaped the development of our practice as teachers. We were educated in Catholic and public school systems in urban centres in Southern Ontario. Similarly, our post-secondary experiences, including our mainstream preservice training, took place in large-scale, westernized institutions in Ontario. Because of these Eurocentric educational experiences as students, our practice as teachers took the same form. It was only during our formative teaching years that we came to some understanding that we were teaching Indigenous students in the same ways that we as non-Indigenous students were taught. This became problematic while teaching in a culturally distinct community with different ways of knowing. Our decisions to pursue graduate school were rooted in a desire to examine critically and to unearth our White privilege. Our desire to examine and unearth our White privilege came about because of a series of encounters in our teaching practice that created points of tension between Eurocentric ways of knowing and Indigenous ways of knowing. For example, one of these points of tension was attendance. Low student attendance resulted in low student success and we became frustrated in our attempts to understand the greater historical discourses such as intergenerational trauma that have an impact on student attendance and achievement.

Our overall purpose in this paper is to speak to some of the experiences, challenges, and opportunities of teaching and living in a First Nations community in Northern Ontario as a means of avoiding the perpetuation of dominant narratives that have and are being told about Indigenous education. In addition, as guest lecturers and instructors in a preservice program in Southern Ontario, it is our aim to institute appropriate and respectful professional practice when teaching non-Indigenous students about Indigenous education. We aim to unpack our experiences as teachers to help us move forward in our understandings as new researchers as well as to respond to a question we are commonly asked, "What is it like to teach in a remote First Nations community in Northern Ontario?" It has been through a series of conversations, sharing of stories, and much dialogue that we have come to a point as graduate students where we are able to look back at our practice as new teachers to help us unpack our privilege as White researchers. Our research questions ask: What can our experiences as nonIndigenous teachers in an Indigenous community offer our understanding as new researchers in the field of Indigenous education, and how can our teaching narratives further preservice teachers' understandings of teaching Indigenous students? Our goal is to further develop and inform preservice teachers' understanding of teaching Indigenous students by responding to our questions through a critical theoretical lens and through narrative inquiry. 


\section{Interrogating Our Whiteness}

Decuir-Gunby (2006) introduces the concept of an all White landscape when he states, "Being White creates a sense of entitlement. Being White means viewing Whiteness as normalcy and is commensurate with exclusive access to societal resources facilitated by other powerful Whites who already utilize this socially inherited racial privilege” (p. 89). Have we been unable to examine how we inherit privilege? This question prompted a retrospective examination of how our teaching experiences continue to influence our current research practices. The privilege accompanying Whiteness is invisible and is continually reinforced and maintained to serve the interests and benefit of the dominant White group (Gillborn, 2006). This critical interrogation of Whiteness calls into question the conception of race, identity politics, and essentialism, all of which surface within our stories. It is important to note that although Whiteness is invisible to those who are White, the privilege associated with Whiteness is evident to those that are not. Critical White studies have assisted us in understanding that our perspective is that of the western education system. We are implicated in this system as students, teachers, and now as researchers. It is from this perspective that we come to unpack and make visible the privileges associated with our Whiteness. Although these are significant areas of inquiry within critical White studies, in this paper, we will explore the invisibility of Whiteness and the shifted gaze for which critical White studies calls. These two notions provide insight and conceptual guidelines that enable us to move toward an understanding of how our Whiteness, privilege, and power as teachers shape our work as new researchers.

Research in race studies is shifting from work about people of colour to include critical White studies, which look inward to the Whiteness that holds up the structures that oppress, discriminate, and marginalize the other. A shifted gaze, which exemplifies this paradigmatic shift in race studies, is demonstrated by Michelle Fine (as cited in Leonardo, 2009) when she says, "I avert my gaze from the inequities produced through colour and turn instead to the merit that accumulates within the hue of Whiteness" (p. 91). The focus of critical White studies allows research and inquiry to focus not solely on Whiteness, but also calls for a critical examination of the structures and institutions that perpetuate, reinforce, and support the invisible privilege that Whiteness holds (Gillborn, 2006). Education, school, and the practice of teaching are the nexuses where these concepts merge and, thus, serve as the sites of our inquiry. This thinking draws out the relationships and connections between the researcher and the researched to unearth and expose the power structures and dominance of the unspoken and normalized. Critical White studies provide the theoretical foundation for this research. As White researchers, we feel immense responsibility to expose the privilege that Whiteness allows as a means of more deeply engaging with our teaching experiences. Critical White studies combined with narrative inquiry centre reflexivity throughout the research process to revisit and reestablish epistemological awareness and philosophical assumptions.

\section{The Power of Narrative Inquiry}

Our interest in narrative inquiry stems back to the question raised above, "Of what stories do I find myself a part?” (MacIntyre, 1981, p. 201). For both of us, our desire to engage in a narrative inquiry originated from having been asked, on numerous occasions, the question, "What is it like to teach in a remote First Nations community?" Whether it was 
around the dinner table with family, at coffee with friends, or out in the greater community, any time the question "What do you do?" was posed, the question would be followed by, "What was it is like? Now, as researchers and graduate students, our colleagues, our preservice students, and the members of our greater university community ask the same question. We came to realize that this question, "What was it like?" was important and deserving of our attention. We found through conversations with one another that our responses to this broad, yet laden, question changed depending on who was asking the question and under what circumstances the question was being posed.

Narrative inquiry revolves around an interest in life experiences as narrated by those who live them and engages with a process of storytelling to further understanding of the relationships between the research and the researcher. In addition, narrative inquiry draws attention to the meaning of our experiences rather than highlighting a series of events. For these reasons, narrative inquiry offers the conceptual categories to guide our inquiry of examining our power and privilege as White teachers and researchers.

Regardless of having lived and taught in a First Nations community, had we really considered the kinds of stories we were telling? Did our stories of teaching and living in Northern Ontario serve as counterstories (Lindemann-Nelson, 1995) aimed at disrupting the dominant, colonial discourse surrounding the context of Indigenous education in Ontario or were they mere re-enactments of the scripts of teaching and learning that we had witnessed and performed throughout our own schooling experiences? To help us move forward in our understandings as new researchers in the field of Indigenous education, we are relying on narrative inquiry as a means to explore further these questions surrounding our practical professional knowledge (Conle, 2000).

Our data sources are our personal narratives that we generated from our time teaching in Northern Ontario. For both of us, our teaching careers began in the community. Dawn taught high school for 3 years and Sarah taught elementary school for 2 years. We have restoried to include rich details about the setting and context of our experiences. We created the characters of Hannah and Marnie to retell our teaching experiences. We chose to write in the third person through these characters to gain new perspective on the stories we told to each other about ourselves. To engage in this process of research from the inside (Mason, 1994), we felt it was integral to employ autoethnographic methods. Over the course of the last year, we have engaged in autoethnographic writing (Chang, 2008) as a means to interpret our teaching experiences. According to Chang (2008), "autoethnographic writings interweave stories from the past with ongoing self-discovery in the present. Stories from the past are interpreted in the context of the present and the present is contextualized in the past” (p. 140). Such a process has the potential to be transformative as the analytic lens turns inward, which provides commensurability with the shifted gaze of critical White studies.

Throughout our dialogue with one other, a variety of stories emerged from our remembered experiences. With each remembering and telling came feelings of vulnerability, for we were disclosing, often for the first time, intimate details from our experiences teaching and living in Northern Ontario. To complicate things further, many of the stories shared between us were shared experiences because we both lived and taught in the same community at the same time. This in itself brought forth unique 
moments of retelling and remembering because we did not always see the same incident or experience in the same way. We identify with what Clandinin (2013) describes as tensions and bumping points in our narratives. As our understanding of both the qualities and methods of narrative inquiry grows, we have begun to recognize how our stories are "both enabled and constrained by a range of social resources and circumstances" (Chase, 2005, p. 657). By attending to these tensions and constraints in our professional practice, we have begun to expose and unearth stories that have remained dormant and undisturbed within us.

The story begins with the start of a new school year as Marnie and Hannah arrive at the airport.

\section{Turbulent Beginnings}

\section{Hannah:}

The humming of the dash-8 engine fills the air as it makes its final descent. It is August $26^{\text {th }}$ and I am on a flight carrying new and returning teachers to the community. We land safely and the engine of the plane quiets. I am one of the last people to step off the plane. My knuckles turn White clutching my carry-on bag. I scan the crowd looking for Marnie, my roommate for the upcoming school year. In my head, I begin to cross things off my to-do list. I have arrived safely, check, I have met Marnie, check.

\section{Marnie:}

Hannah shouts from the passenger seat of the pickup truck, "Hey Marnie, are you getting in the back? It's full up here." The back wheel of the pickup truck must be at least a foot high. I hitch my leg up and place my foot on the wheel, throwing my backpack in the bed of the truck. Jumping in the back of a pickup isn't exactly a skill I had learned as a suburbanite. The blackness of the night falls over me as the truck bumps quietly along. I am alone in the back of the pickup, unaware of what important information is being translated from our host to Hannah and the other teachers who had quickly assumed positions within the vehicle. Strangely, I like the bumpy silence and I know that in this moment I am where I need to be. We pull up to a cluster of houses and our host calls our names. I jump out of the truck to join Hannah as the host hands me the keys to what will be our home for this next year. The tail lights of the truck beam through the darkness as we are left alone to begin the journey that will forever change our worlds. The key turns and the lock clicks. We stare down a long, dark hallway. We are home.

\section{Hannah:}

As I look down the long, dark hallway, I find the light that reveals a furnished living room, kitchen, and dining room. As I look through the cupboards in the kitchen, I realize everything I need is here. I have what I need to survive, check. 
Three years have passed since we called ourselves northern teachers. We have been away from the community longer than we lived there, yet it seems like only yesterday that we each made the trek from Southern Ontario to Northern Ontario to begin what has been one of the most rewarding, yet challenging chapters in our professional and personal lives. The experience of being a teacher in Ontario's north draws questions from those within and beyond the educational community regarding the motivation to assume and maintain a teaching position in a northern location. Among the most popular is the question, "What is it like to teach in a remote First Nation community?" While each of us would describe our teaching experiences in Northern Ontario as distinctly unique, the commonality we share is the impact our experiences have had on how we negotiate our roles as educators, researchers, and as individuals in the present.

The decision to share our stories with each other, the task of physically putting the words on paper for you, the reader, and then, finally, the examination of our narratives through researchers' eyes was, at times, uncomfortable. Phillion (2002) states that "narrative inquiry is as much about learning about and using one's prisons, one's unexamined biases and assumptions, one's unacknowledged desires, as it is about learning about and using one's strengths” (p. 542). It was difficult to revisit our teaching experiences because it required us to confront experiences and emotions that we were not always convinced we were ready to confront. Graduate school has provided an avenue from which we can learn with others who similarly seek answers to difficult questions surrounding race, privilege, and power. These complex issues have become intertwined with our professional and personal lives and they have often left us feeling exposed, discouraged, and ashamed. However, it is only in these moments of discomfort that our understandings can evolve and new knowledge can be found, even if it requires wandering and perhaps getting lost in the process. Reminded by the words of Bishop (2002), "guilt means taking on all the weight of history as an individual; responsibility means accepting your share of the challenge of changing the situation" (p. 115), we are finally ready to restory our teaching narratives from a position of complacency and unknowing to a position of acknowledgement and understanding.

\section{Beyond the Line}

On Monday morning, Marnie stands at the door with a zipped up parka and laced up boots while Hannah works to secure the buttons on her coat and fumbles with her mitts. Winter in the North is marked not only by snow but also by ice. When it is really cold, the snow squeaks beneath your feet and your nostrils freeze together. Marnie shouts to Hannah, "Good luck with your line today." Hannah turns back and a forced smile spreads across her face. "Thanks," she mumbles. Hannah has been working diligently with her students to form a single file line. Each attempt, a bigger failure than the previous. While Hannah's Grade 3 class moves in blob formation, the other Grade 3 class stands tall and militant in a single file line that could compete with high school marching bands walking in the Rose Bowl parade. Hannah's frustration and impatience grows and begins to boil over beyond the line and into the cracks and crevices of the teaching day. After a particularly challenging morning, Hannah stomps home for lunch exasperated to meet Marnie in the kitchen 
making a grilled cheese sandwich. Stomp, stomp, stomp, stomp, stomp. There are five stairs up to the kitchen and Hannah makes good use of each one. Marnie flips her grilled cheese and it sizzles, as do the red-hot tears in Hannah's eyes. "How was your morning, Hannah?” My kids suck. I am the worst teacher ever. I can't even get them to stand in a straight line." Hannah's face is the same colour as the ketchup Marnie squeezes onto her plate. After some ranting and self-doubt from Hannah, Marnie asks, "Why does it matter if your students stand in a line? What is the purpose of having a line? Are you really worried about the line or are you worried about how you will be perceived from other teachers if you do not have a line?" After some contemplation and a grilled cheese, the tears disappear just like the ketchup on Marnie's plate. Hannah picks her parka up and goes back to school.

By Friday, Hannah has been hit with a wave of exhaustion. It takes all of her energy to hang her parka up in the hallway closet. She lowers the blinds, seeking refuge in the cloud of darkness that envelops her. She desperately tries to quiet the chaos of the past week as it replays through her mind; the shouts of unruly kids, the unsuccessful attempts to have her students walk in a straight line, the tears of frustration forming in William's eyes after a particularly drawn out battle to have him complete his work. In thinking back, Hannah realized it was at that moment, seeing William cry, that she had lost control. Now the voice of Marnie played in Hannah's mind when she questioned her preoccupation with having her students be able to form a straight line.

All throughout her own schooling, Hannah knew what she was working toward... An A on a paper, a university degree, a career in education. Now she was lost. Hannah so desperately wanted to be a "good" teacher, well-liked by her students, respected by their parents, and accepted by the community. "I deserve to be here just as much as anyone else,, she kept telling herself. But if anything had become apparent in the last week it was how skewed Hannah's understanding of what it meant to be a "good" teacher had become. On paper, she knew what a good teacher looked and sounded like, but in reality, Hannah could not deliver a believable performance. This week and others like it had left her feeling unsure of herself. Perhaps Marnie was on to something. Why was she so concerned with having her students form a straight line? Did she fear others would ridicule her teaching and by extension her too?

\section{Reflections on "Beyond the Line"}

"Beyond the Line" offers a succinct opportunity for analysis and helps understand the positionality of Hannah as she struggles with challenges faced in her teaching practice. It was not until examining this narrative through the conceptual categories of critical White studies that I, Sarah, was able to recognize the power and privilege my skin colour granted me. Initially, I felt ashamed and embarrassed at what my privilege had afforded me. However, as I continue to engage in reflection, I have grown increasingly angry and 
disappointed at the educational system for perpetuating an ideal that the White way is the right way and the only way to find educational success. In conversation with Dawn, I realized how, through my actions, I had been exerting on my students certain beliefs about power and control, demonstrating an underlying epistemological belief that the teacher is part of a hierarchical system that positions them as the knowledge holders, a common framework in Eurocentric approaches to education. It was important to me that my students stand in a straight line because it represented my ability as a teacher to have control and maintain order over my students, which I had thought and been taught to see as an admirable attribute in a good teacher. I also saw a straight line as a safety measure to keep students accounted for. At the time, I had not considered how my students would be impacted by my unrelenting efforts to force them into a line. Perhaps they did not value a line as I did. Perhaps they felt constrained. Perhaps they felt safer not in a line. In addition, Hannah's dialogue throughout this narrative emphasizes an individualized rather than a collective understanding of education, perpetuating the ongoing colonial divide between Indigenous and western ways of knowing.

I now recognize that the feelings of powerlessness I felt in my first years of teaching were what Clandinin, Murphy, Huber, \& Orr (2010) describe as "conflicting stories." According to Clandinin et al. (2010), conflicting stories "collide with dominant stories of school" (p. 82). Having been educated in an educational system that places greater value on Eurocentric views, I realize my struggle for control stems from the lack of understanding I had of other ways of knowing. I had become a product of a curriculum that did not address how relationships between Indigenous and non-Indigenous people originated, the impact colonialism has had on First Nations communities in Canada, and its implications for Indigenous people today. How could I provide my students with what they needed when I had not received the training, support, and resources required to deliver appropriate educational programming? For years, I had been taught not to see my Whiteness, to assume a position of colour-blindness. It was not until I had begun teaching in a cultural context different from my own that I realized the prevailing discourses that had normalized my understanding of the purpose and practices of school. In some ways, my individual capacity to act as an agent of change was suppressed due to my position within the social, political, and historical structures of society. Is it possible to be in a position of privilege and simultaneously to feel oppressed by the structural forces that have socially constructed such positions of power? I think so. I had been educated to follow a particular script that eventually led me to my professional failure when I realized what I had conceived as normal or natural conflicted with another group's understanding of the nature of knowledge.

\section{Marnie's Parka}

I wear my parka as if it's an extension of my physical self. The feathers inside form around the shapes that make up my body and the hood falls perfectly over my head to block out the wind and the blowing snow. All winter, I go through the same routine at least four times a day, pull the parka down from the hook and throw it over my shoulders, finding the zipper end in one fell swoop. It zips up high and the hood falls over my head revealing nothing but the details on my face. I have become attached to my parka because it has protected me from the cold blasts of winter air 
and has become a part of me. Everywhere I go, there it is, hanging on a hook, waiting for me.

In the early spring, the snow doesn't quite melt but it becomes softer and I can start to feel the heat from the sun on my face. I unzip my parka just a bit revealing the collarbones that have not seen the sun since the late summer. I feel exposed but liberated with the thought that my parka might stay home while I am not. Soon enough the snow actually starts to melt and my parka rests on its hook. I place my hand on the hood and hesitate while I look out the window. It looks warm enough, maybe I can wear something else, I consider. Nope, not yet. I am not ready to leave my parka behind.

When the snow is nearly gone, and the green ground starts to emerge, I consider, along with new life, what will become of my life. Will I return to this place or move on? Contract renewals happen in the spring and my decision-making process is much like deciding to let go of my parka. Will I need it? What will I do without it? Will I be exposed to the elements? My time living and teaching here has become comfortable; this is home, and this is my normal. How will I survive without this? Can I survive without this?

I relish the liberation of my first trip out the door without my parka. I feel lighter and more movable, maybe even taller. I can feel the breeze blowing on the back of my neck and the sun touching my ear. I like how this feels and the opportunities ahead seem boundless as the summer approaches.

The walk across the runway toward the airplane seems unreal, as it will be my last. Hannah motions to the kids at the fence, yelling and waving goodbye, as we walk toward the aircraft. I can feel the sun again but this time it's on my arms; I am not wearing a parka or even a coat. I feel the elements, I hear the kids and I see the plane that will take me onward. My parka remains on its hook. There is a slight chill in the air.

In October, Hannah and I walk home from our graduate classes and I still revel in the heat of the sun. I can feel it turn my black hair hot. I don't need a parka now in the city; I probably never will and although I don't wear one, I feel the weight of it on my shoulders. I remember the feathers that kept me warm and the hood that protected me. That parka is still a part of me and always will be.

\section{Reflections on "Marnie’s Parka"}

The meaning of "Marnie's Parka" runs much deeper than simple protection from the elements and representations of the seasons. Marnie's parka offers an analogy to explore the meaning of Whiteness and the protection and power so deeply associated with the experience of teaching in a remote First Nations community. While living in a culturally distinct community, where being White meant being an outsider, having the coverage and 
protection of a thick outer layer provided a means to blend in and further deepen the invisibility of my White privilege.

The invisibility of White privilege is not invisible to those who are not White. Learning this lesson revealed interesting behavior on my part as I took solace in not being noticed, and subconsciously worked to blend in. It was as though dealing with the privilege of being White was too much to handle so I literally covered up as a means to resist the issues of race that so dominantly dictated my daily experiences. Soon enough, however, I realized the parka was not protecting me anymore and the inequities around me were too strong to ignore, too impactful for me to continue my resistance to explore my own Whiteness.

While teaching and living in a context wrought with poverty and inequities, I could choose to either engage with these issues around me or not to because I was only a visitor and I could, when I chose to do so, leave the community and re-enter a world where the inequities were less visible and part of my everyday experience. This sense of mobility and movement beyond the inequities is a strong indicator of the privilege associated with my Whiteness. The inequities were temporary to me because I did not think I was implicated. However, my Whiteness and its associated power were established based on the disadvantages of the oppressed. This choice, this privilege, was not afforded to the students I taught or to their families because they lived outside the hue of White. I was in a position of power to have not only the economic means but also the cultural capital to leave the community and comfortably exist in the South and beyond. It was as though I could remove my parka and engage with the community when I wanted to and then cover up when it got too personal, when it got too difficult, when it became more than what I knew how to comprehend. This single choice, opportunity, and way of thinking, demonstrates the power and privilege associated with my Whiteness, which became amplified in a cultural context where I was not the majority.

Even through this analysis, I have come to realize that I am still working through and unpacking my privilege. For example, in review of this analysis, it was brought to my attention that my use of the term visitor could be problematized. By referring to myself as only a visitor, I did not consider how this could affect my students, their parents, and the greater community's perspectives of me. Did my time teaching in the community facilitate the development of more long lasting relationships? If I see myself as a temporary visitor, my students, their parents, and the community may question my intentions and commitment to their education. The role of a visitor could be seen as temporary and perhaps self-serving, neither of which lend themselves to establishing strong and long lasting relationships within the school community. Although this narrative serves to disrupt my Whiteness, I acknowledge that I am unable to see all the privileges my Whiteness affords. Nevertheless, without this theoretical position and process of analysis, I would not have seen my privilege and Whiteness within my teaching experiences.

Moving forward to graduate school is yet another example of a series of opportunities facilitated by the privileges that Whiteness affords me. It has only been since leaving the community that I have been able to further engage and authentically explore the meaning of my own Whiteness, but questions remain: Am I only able to 
explore the meanings and power of White privilege within a system of education that works toward maintaining the invisibility of White power? What else remains invisible to me? Despite the questions, I have started to understand that my Whiteness offered me privilege, power, protection, and opportunities that my First Nation students did not and do not have. In teaching, I often assumed my students had all the same opportunities I had, but they did not necessarily. Understanding the power associated with the hue of Whiteness helps me to break apart those assumptions and in turn start to explore further the inequities in Indigenous education and my role within them.

\section{Revisiting}

Our decision to pursue this inquiry was rooted in a desire to critically examine and unearth our White privilege so that we could begin the journey of reflecting upon our practice as both teachers and researchers. Specifically we asked, "What can our experiences as non-Indigenous teachers in an Indigenous community offer us in our understanding as new researchers in the field of Indigenous education? Using critical White studies and narrative inquiry, we have found that the stories we tell about our experiences teaching in the North are grounded in our Eurocentric educational experiences and ways of knowing. Not only does our Eurocentrism affect our teaching practices, but also it influences our experiences as students in preservice programming, developing how we see ourselves as teachers. In doing this work, we have examined our experiences as a means to make visible the colonial structures and systems in education. We acknowledge that this work is part of a larger process with which we engage in ongoing critical analysis of how Whiteness and privilege influences our practice.

We have also asked, "How can our teaching narratives further preservice teachers' understandings of teaching Indigenous students?" Through the conceptual categories of critical White studies, we saw something in our stories that had been invisible to us before-our Whiteness. As preservice teachers, we did not have the opportunity to understand our White privilege, but through this research we have made visible what was previously unseen to us. Schick and St. Denis (2005) argue, "The narrative of the nation as raceless, benevolent, and innocent has implications for the reproduction of racial privilege” (p. 296). In order to interrupt the reproduction of racial privilege, preservice teachers, both Indigenous and non-Indigenous should have the opportunity to critically engage and question their own power and privilege. Our stories offer preservice teachers insight into not only the experiences of new teachers working in an Indigenous context but also the intersection of White privilege and education. Exploring the implementation of preservice programming that addresses issue of White privilege is an extension of this research. The next step is to examine critically preservice curriculum to find opportunities of where issues of race, power, and privilege can be addressed.

\section{Conclusion}

By revisiting our teaching experiences through autoethnographic methods, we have shared our experiences and the meaning we make of them. We offer these stories as lessons of practice with hopes that preservice teachers, new to the profession, can begin to understand what it was really like for us to teach in a remote First Nations community. It is our intention that this inquiry serve to expose the inherent power and privilege upon 
which our professional practices have been founded. The stories of Marnie and Hannah offer poignant opportunities to interrogate positionality as non-Indigenous teachers and researchers in the field of Indigenous education. This work serves to unmask what Whiteness has provided and how it has shaped our understandings of teaching and learning. In addition, these narratives resist and disrupt the discourse of Eurocentrism that dominates the education system by questioning positions of privilege, race, and power. It is only through such a process that teachers can begin to disrupt the destructive and deeply ingrained colonial attitudes and patterns of behavior that permeate not only current educational infrastructures but also the people who participate and engineer the infrastructures that guide our actions. 


\section{References}

Bishop, A. (2002). Becoming an ally: Breaking the cycle of oppression in people. (2nd ed.). Halifax, NS: Fernwood Publishing.

Chang, H. (2008). Autoethnography as method. Walnut Creek, CA: Left Coast Press.

Chase, S. E. (2005). Narrative inquiry: Multiple lenses, approaches, voices. In N. K. Denzin \& Y. Lincoln (Eds.), The Sage handbook of qualitative research (3rd ed., pp. 651-679).Thousand Oaks, CA: Sage.

Clandinin, J. (2013). Engaging in narrative inquiry. Walnut Creek, CA: Left Coast Press.

Clandinin, D. J., Murphy, S. M., Huber, J., \& Orr, A. M. (2010). Negotiating narrative inquiries: Living in a tension filled midst. The Journal of Educational Research, 103, 81-90.

Conle, C. (2000). Narrative inquiry: Research tool and medium for professional development. European Journal of Teacher Education, 23(1), 49-63.

Decuir-Gunby J. T. (2006). Proving your skin is White, you can have everything: Race, racial identity, and property rights in Whiteness in the supreme court case of Josephine DeCuir. In A. D. Dixson \& C. K. Rousseau (Eds.), Critical race theory in education: All God's children got a song (pp. 89-111). New York, NY: Routledge.

Gillborn, D. (2006). Rethinking White supremacy: Who counts in 'Whiteworld'. Ethnicities, 6(3), 318-340.

Leonardo, Z. (2009). Race, Whiteness, and education. New York, NY: Routledge.

Lindemann-Nelson, H. (1995). Resistance and insubordination. Hypnatia, 10(2), 23-40.

MacIntyre, A. (1981). After virtue: A study in moral theory. Notre Dame, IN: University of Notre Dame Press.

Mason, J. (1994). Researching from the inside in mathematical education: Locating an Iyou relationship. Centre for Mathematics Education. Milton Keynes, England: Open University.

Phillion, J. (2002). Becoming a narrative inquirer in a multicultural landscape. Journal of Curriculum Studies, 34(5), 535-556.

Schick, C., \& St. Denis, V. (2005). Troubling national discourses in anti-racist curricular planning. Canadian Journal of Education, 28(3), 295-317. 